\title{
Methylation of Salmonella Typhimurium flagella promotes bacterial adhesion and host cell invasion
}

Julia A. Horstmann ${ }^{1,2,13}$, Michele Lunelli ( ${ }^{3,13}$, Hélène Cazzola ${ }^{4}$, Johannes Heidemann ${ }^{5}$, Caroline Kühne ${ }^{6}$, Pascal Steffen ${ }^{7}$, Sandra Szefs ${ }^{1}$, Claire Rossi ${ }^{4}$, Ravi K. Lokareddy ${ }^{8}$, Chu Wang ${ }^{3}$, Laurine Lemaire ${ }^{4}$, Kelly T. Hughes ${ }^{9}$, Charlotte Uetrecht (10 ${ }^{5,10}$, Hartmut Schlüter ${ }^{7}$, Guntram A. Grassl ${ }^{11}$, Theresia E. B. Stradal (1) ${ }^{2}$, Yannick Rossez ${ }^{4}$, Michael Kolbe ${ }^{3,12,14 凶}$ \& Marc Erhardt (iD) 1,6,14凶

The long external filament of bacterial flagella is composed of several thousand copies of a single protein, flagellin. Here, we explore the role played by lysine methylation of flagellin in Salmonella, which requires the methylase FliB. We show that both flagellins of Salmonella enterica serovar Typhimurium, FliC and FljB, are methylated at surface-exposed lysine residues by FliB. A Salmonella Typhimurium mutant deficient in flagellin methylation is outcompeted for gut colonization in a gastroenteritis mouse model, and methylation of flagellin promotes bacterial invasion of epithelial cells in vitro. Lysine methylation increases the surface hydrophobicity of flagellin, and enhances flagella-dependent adhesion of Salmonella to phosphatidylcholine vesicles and epithelial cells. Therefore, posttranslational methylation of flagellin facilitates adhesion of Salmonella Typhimurium to hydrophobic host cell surfaces, and contributes to efficient gut colonization and host infection.

\footnotetext{
${ }^{1}$ Junior Research Group Infection Biology of Salmonella, Helmholtz Centre for Infection Research, Inhoffenstraße 7, 38124 Braunschweig, Germany.

${ }^{2}$ Department of Cell Biology, Helmholtz Centre for Infection Research, Inhoffenstraße 7, 38124 Braunschweig, Germany. ${ }^{3}$ Department for Structural Infection Biology, Center for Structural Systems Biology (CSSB) \& Helmholtz Centre for Infection Research, Notkestraße 85, 22607 Hamburg, Germany. ${ }^{4}$ Université de Technologie de Compiègne, Alliance Sorbonne Université, UMR7025 CNRS Enzyme and Cell Engineering Laboratory, Rue Roger Couttolenc, CS 60319,60203 Compiègne, Cedex, France. ${ }^{5}$ Heinrich Pette Institute, Leibniz Institute for Experimental Virology, Martinistraße 52, 20251 Hamburg, Germany. ${ }^{6}$ HumboldtUniversität zu Berlin, Institute for Biology - Bacterial Physiology, Philippstr. 13, 10115 Berlin, Germany. ${ }^{7}$ Institute of Clinical Chemistry and Laboratory Medicine, Mass Spectrometric Proteomics Group, University Medical Center Hamburg-Eppendorf, Martinistrasse 52, 20246 Hamburg, Germany. ${ }^{8}$ Department of Biochemistry and Molecular Biology, Thomas Jefferson University, 1020 Locust Street, Philadelphia, Pennsylvania 19107, USA. ${ }^{9}$ University of Utah, Department of Biology, Salt Lake City, UT 84112, USA. ${ }^{10}$ European XFEL GmbH, Holzkoppel 4, 22869 Schenefeld, Germany. ${ }^{11}$ Institute of Medical Microbiology and Hospital Epidemiology, Medizinische Hochschule Hannover, and German Center for Infection Research (DZIF), Partner Site HannoverBraunschweig, Carl-Neuberg-Str. 1, 30625 Hannover, Germany. ${ }^{12}$ MIN-Faculty University Hamburg, Rothenbaumchaussee 19, 20148 Hamburg, Germany.

${ }^{13}$ These authors contributed equally: Julia A. Horstmann, Michele Lunelli. ${ }^{14}$ These authors jointly supervised this work: Michael Kolbe, Marc Erhardt.

凶email: michael.kolbe@helmholtz-hzi.de; marc.erhardt@hu-berlin.de
} 
$\mathrm{T}$ he Gram-negative enteropathogen Salmonella enterica serovar Typhimurium (Salmonella Typhimurium) uses a variety of strategies to successfully enter and replicate within a host. In this respect, bacterial motility enables the directed movement of the bacteria towards nutrients or the target site of infection. A rotary nanomachine, the flagellum, mediates motility of many bacteria, including Salmonella Typhimurium ${ }^{1}$. Flagella also play a central role in other infection processes, involving biofilm formation, immune system modulation, and adhesion $^{2-5}$.

The eukaryotic plasma membrane plays an important role in the interaction of flagellated bacteria with host cells during the early stages of infection ${ }^{6}$. The flagella of Salmonella Typhimurium, Escherichia coli and Pseudomonas aeruginosa can function as adhesion molecules ${ }^{7-9}$ mediating the contact to various lipidic plasma membrane components, including cholesterol, phospholipids, sulfolipids and the gangliosides GM1 and aGM1 ${ }^{10-13}$.

Structurally, the flagellum consists of three main parts: the basal body embedded within the inner and outer membranes of the bacterium, a flexible linking structure-the hook, and the long, external filament, which functions as the propeller of the motility device ${ }^{14}$. The filament is formed by more than 20,000 subunits of a single protein, flagellin ${ }^{15}$. Many S. enterica serovars express one of two distinct flagellins, FliC or FljB, in a process called flagellar phase variation ${ }^{16}$. FliC-expressing bacteria display a distinct motility behavior on host cell surfaces and a competitive advantage in colonization of the intestinal epithelia compared to FljB-expressing bacteria ${ }^{17}$. However, while the structure of FliC has been determined previously ${ }^{18}$, the structure of $\mathrm{FljB}$ remained unknown.

The many thousand surface-exposed flagellin molecules are a prime target of the host's immune system. Accordingly, many flagellated bacteria have evolved mechanisms to prevent flagellin recognition, e.g. by posttranslational modifications of flagellin. Flagellin glycosylation is relatively common among Enterobacteriaceae $^{19}$, in Campylobacter, Aeromonas, and Pseudomonas species $^{20-22}$ and plays a critical role in adhesion, biofilm formation or mimicry of host cell surface glycans ${ }^{23}$.

Salmonella Typhimurium does not posttranslationally glycosylate its flagellins. However, $\varepsilon$-N-methylation at lysine residues of flagellin via the methylase FliB has been reported $24-26$. Although flagellin methylation was first reported in $1959^{25}$, the physiological role of the methylation remained elusive. Previous studies suggested that the absence of FliB had no significant effect on swimming and swarming motility 27,28 . However, the conservation of flagella methylation in Salmonella and other Enterobacteriacea ${ }^{19}$ suggests that methylated flagella are important for some other aspect of the life style of the bacteria. In the present study, we therefore investigated the hypothesis that flagella methylation contributes to some aspect of virulence of Salmonella Typhimurium.

We find that methylation of flagella facilitates adhesion of Salmonella Typhimurium to hydrophobic host cell surfaces. Thus, the posttranslational methylation of flagellin plays an important role for invasion of host cells, and accordingly, productive colonization of the host's epithelium.

\section{Results}

Methylated lysines residues in flagellin and structure of FljB. Previous studies suggested that the flagellins of Salmonella Typhimurium are posttranslationally methylated, however, the identity of the methylated lysine residues remained largely unknown ${ }^{25,26,29}$. We performed mass spectrometry analyses with high sequence coverage of both flagellins $\mathrm{FliC}$ and $\mathrm{FljB}$ isolated from Salmonella Typhimurium genetically locked in expression of $\mathrm{FliC}\left(f l i \mathrm{C}^{\mathrm{ON}}\right)$ or $\mathrm{FljB}\left(f l j B^{\mathrm{ON}}\right)$, respectively, and isogenic mutants of the methylase FliB $(\Delta f l i B)$ (Supplementary Fig. 1). In order to map the identified $\varepsilon$ - $\mathrm{N}$-methyl-lysine residues to the structure of both flagellins, we determined the crystal structure of FljB (Fig. 1, Supplementary Note 1). The tertiary structure of FljB resembles, similar to $\mathrm{FliC}$, a boomerang-shape with one arm formed by the $\mathrm{D} 1$ domain and the other formed by $\mathrm{D} 2$ and $\mathrm{D} 3^{18}$. However, the variable D3 domain of $\mathrm{FljB}$ is rotated about $90^{\circ}$ around the axis defined by the D2-D3 arm compared with FliC, resulting in the widening angle of about $20^{\circ}$ between the two boomerang arms, consistent with the recently reported structure of flagellar filaments composed of FljB by cryo-electron microscopy $^{30}$ (Fig. 1b, c, Fig. 2a). Interestingly, the methylated lysine residues are primarily located in the surface-exposed D2 and D3 domains of both flagellins (Fig. 1d, Fig. 2a, Supplementary Note 2). Notably, except for two lysines in FliC and three in FljB, the detected lysine residues were methylated only in the presence of the methylase FliB and most of the lysines conserved between both flagellins were methylated (Fig. 1d, Supplementary Note 2).

We next aligned the amino acid sequences of FljB and FliC upand downstream of the identified $\varepsilon$-N-methyl-lysine residues $( \pm 6$ residues, Supplementary Fig. 2). Although no clear consensus sequences could be determined, we found prevalence of small (Ala, Gly, Thr, Val, Ser) and negatively charged (Asp) residues around the methylated lysines. Interestingly, a scan of the local amino acid sequences that surround methylated lysines using ScanProsite ${ }^{31}$ matched the profile of the bacterial Ig-like domain 1 (Big-1) for 10 modifications in both FljB and FliC, although with low confidence level (Supplementary Table 2). We note that the Big-1 domain is present in adhesion proteins of the intimin/invasin family, which are crucial in bacterial pathogenicity mediating host-cell invasion or adherence $32-34$, suggesting a similar role for bacterial flagellins. Due to the absence of a clear amino acid consensus sequence, we next investigated the secondary structure elements around the methylation sites. We could not, however, identify a specific, conserved secondary structure element (Supplementary Fig. 3). We note that the low number of modified lysines in helices can be explained with the scarcity of this secondary structure element in the D2 and D3 domains.

Flagella methylation contributes to host cell invasion. We next investigated if methylation of $\mathrm{FliC}$ and $\mathrm{FljB}$ affects flagellar assembly and motility in Salmonella Typhimurium. The levels of non-methylated flagellin secreted from a $\Delta f l i B$ mutant strain were comparable to secretion of methylated FliC or FljB (Fig. 3a). Immunostaining of flagella from the WT and a $\Delta f l i B$ mutant strain revealed no significant differences in flagella assembly and flagella numbers per cell body (WT $=2.2 \pm 1.8 ; \Delta f l i B=2.2 \pm 1.5$ ) (Fig. 3b). In agreement with earlier reports ${ }^{27,28}$, swimming motility of $\Delta f l i B$ mutant strains in semi-solid agar plates was also not affected (Fig. 3c).

The absence of a motility phenotype in non-methylated flagellin mutants suggested that flagellin methylation might play a role in Salmonella virulence. We thus co-infected streptomycinpre-treated mice ${ }^{35}$ with the wildtype (WT) and an isogenic $\Delta f l i B$ mutant (Fig. 2b). Organ burden analysis 2 days post-infection revealed that the $\Delta f l i B$ strain was significantly outcompeted by the WT in the gastroenteritis mouse model, especially in the cecal tissue (Fig. 2b, competitive indices $>1$ ), suggesting that methylated flagella appear to enhance efficient colonization of the intestinal epithelium.

We next tested if methylated flagella contribute to efficient adhesion and invasion of epithelial cells in vitro (Fig. 4a). We first infected murine MODE-K epithelial cells with the WT and Salmonella Typhimurium strains deficient in the methylase FliB 
a

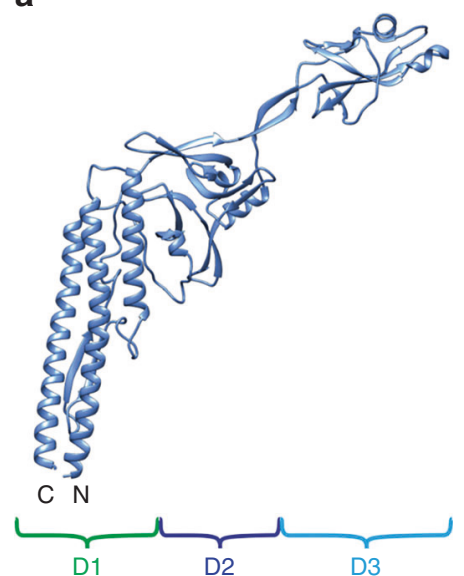

b

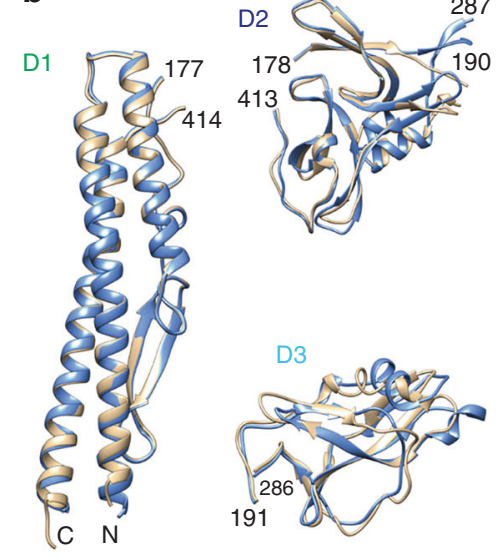

C

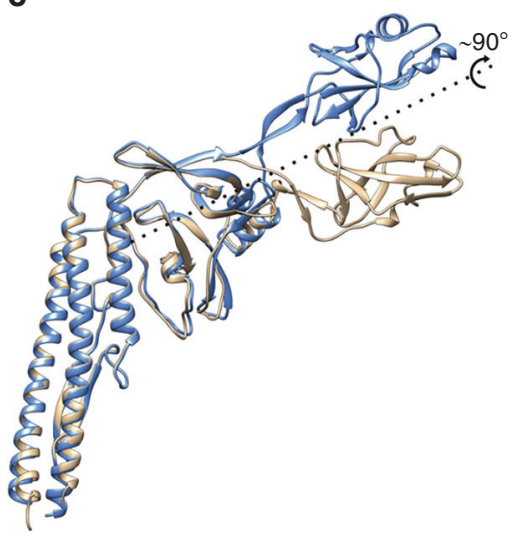

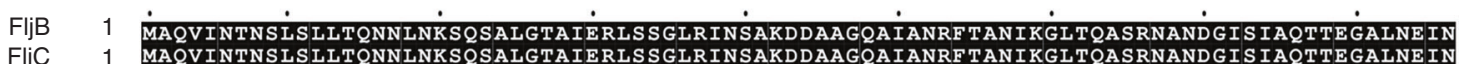

D1

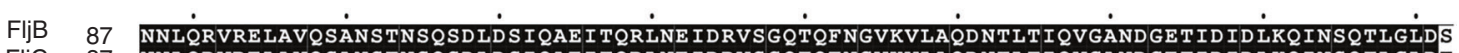

FliC 87 NNLQRVRELAVQSANSTNSOSDLDSIQAEITQRLNEIDRVSGQTQFNGVKVLAODNTLTIQVGANDGETIDIDLKOINSQTLGLDT

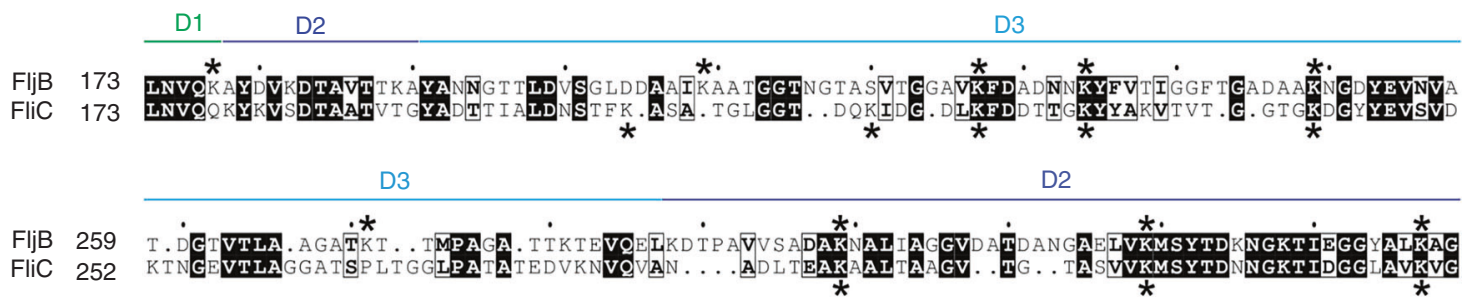

D2

D1

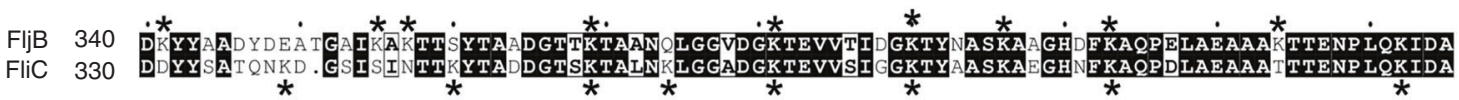

D1

DO

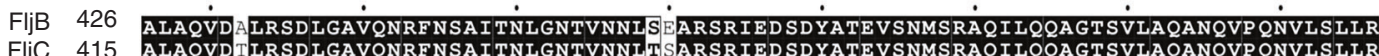

Fig. 1 Structure of FljB and methylation pattern of the flagellins FliC and FljB. a Cartoon representation of the structure of truncated FljB. The position of the $\mathrm{N}$ - and $\mathrm{C}$-termini is shown at the end of the coiled-coil, and the extension of the domains D1, D2, and D3 is indicated below the structure. $\mathbf{b}$ Structural superposition of the individual domains. FljB domains are represented in blue, FliC in beige. The $\mathrm{N}$ - and $\mathrm{C}$-termini of the structure are indicated, as well as the FljB numbering of the residues at the ends of the polypeptide segments defining the domains. $\mathbf{c}$ The structures of truncated FljB (blue) and truncated FliC (beige) have been superposed according to the D1 and D2 domains. The domain D3 shows a rotation of about $90^{\circ}$ around an ideal axis starting from one end of the coiled-coil in D1 and passing through D2 (shown as dotted line). $\mathbf{d}$ Alignment of FljB and FliC and methylation pattern. Residues of domains D1, D2, and D3 have been aligned based on the structural superposition obtained with the EBI PDBeFold v2.59 server (51), either superposing the D1-D2 domains or the D3 domain. Residues of domain D0 have been aligned based on the sequence. The extent along the sequence of the domains is indicated above the alignment. Methylated lysine residues are indicated with stars above or below the alignment for FljB or FliC, respectively.

and determined the number of intracellular bacteria. Invasion was reduced about $50 \%$ for the $\Delta f l i B$ mutant strain independently of the flagellin type (Fig. 4b, top). We also observed a similar invasion defect for the $\triangle f l i B$ mutant when we forced contact of the bacteria with the epithelial cells using centrifugation (Fig. $4 \mathrm{~b}$, bottom), suggesting that the invasion defect of the $\Delta$ fliB mutant did not depend on active bacterial motility. We next confirmed that the observed invasion phenotype was due to the lack of $f l i B$ by complementing expression of $f l i B$ from an inducible $\mathrm{P}_{\text {tet }}$ promoter at its native chromosomal locus. Addition of anhydrotetracycline $(\mathrm{AnTc})$ induced $f l i B$ expression comparable to levels of the WT and restored invasion of MODE-K epithelial cells (Supplementary Fig. 4). We further tested if the observed invasion defect was dependent on the assembly of the methylated flagellar filament. A hook deletion mutant $(\triangle f l g E)$ does not express flagellin, whereas a mutant of the hook-filament junction proteins $(\triangle f l g K L)$ expresses and secretes flagellin, but does not assemble the flagellar filament. The methylase FliB is expressed in both $\triangle f l g E$ and $\triangle f l g K L$ mutant backgrounds ${ }^{27}$. We observed in neither the $\triangle f l g E$ nor the $\Delta f l g K L$ mutant a difference in MODE-K epithelial cell invasion in the presence or absence of FliB, suggesting that methylated flagellin must assemble into a functional flagellar filament in order to facilitate epithelial cell invasion (Supplementary Fig. 5). 
a

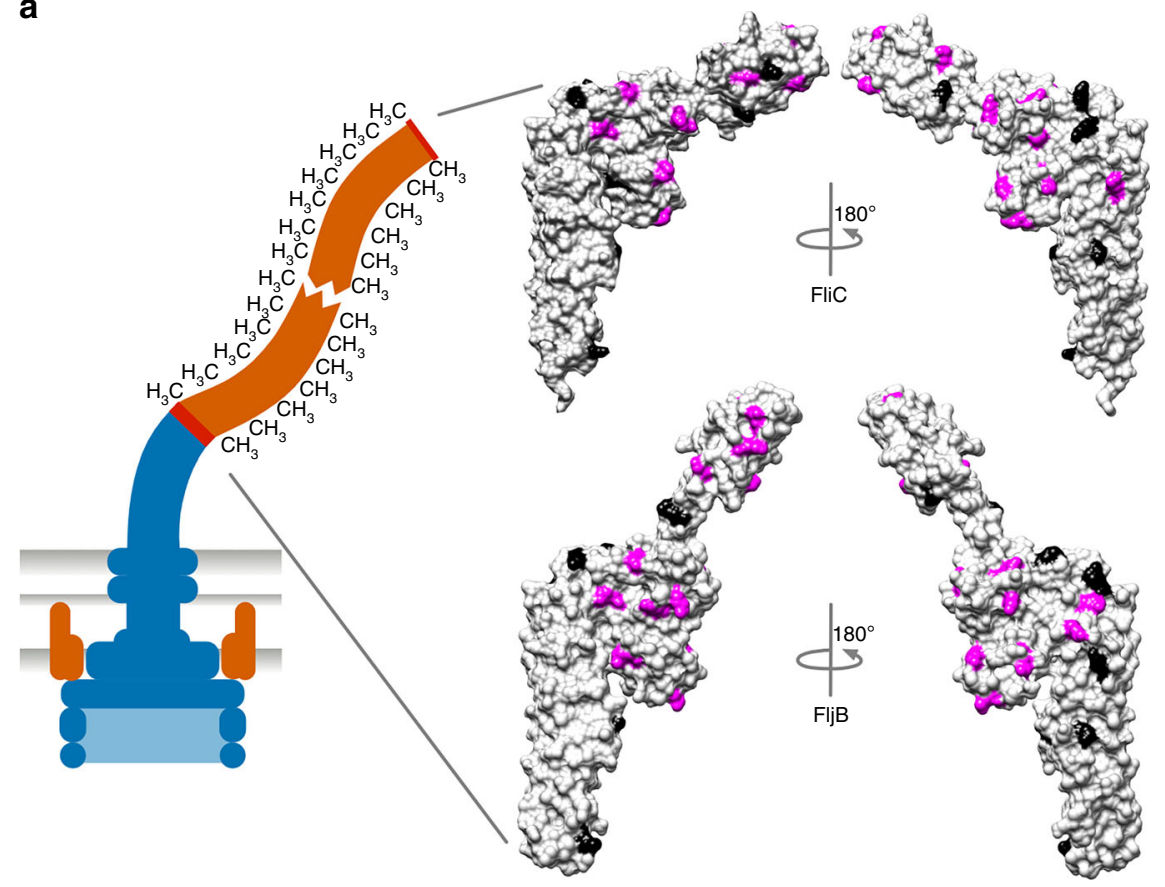

b

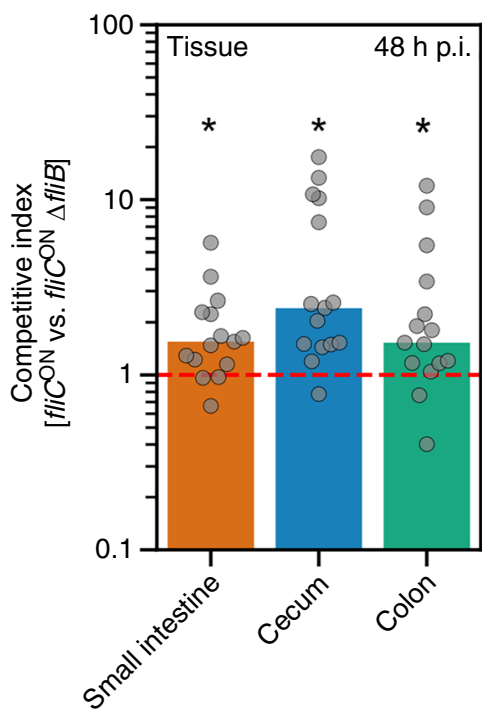

Fig. 2 Surface-exposed methylation of flagellin contributes to efficient colonization of the murine intestine. a Schematic of a methylated flagellar filament and surface representation of the structure of FliC (top) and FljB (bottom). Methylation sites are highlighted in magenta and non-methylated lysines in black. b Streptomycin pre-treated C57BL/6 mice were infected with $10^{7} \mathrm{CFU}$ of the FliC-expressing WT (fliCON) and isogenic $\Delta$ fliB mutant, each harboring a different antibiotic resistant cassette. The organ burden (small intestine, colon and cecum, respectively) was determined 2 days post-infection and used to calculate the competitive indices $(\mathrm{Cl})$. Each mouse is shown as an individual data point and significant differences were analyzed by a two-tailed Wilcoxon Signed Rank test. The bar graph represents the median of the data and asterisks indicate a significantly different phenotype to the value $1{ }^{*}=p<0.05$. WT vs. $\Delta$ fliB small intestine: $p=0.0135$, WT vs. $\Delta$ fliB cecum: $p=0.010$, WT vs. $\Delta$ fliB colon: $p=0.0384$ ). $n=15$ biologically independent animals. Source data are provided as a Source Data file.

Methylated flagella facilitate bacterial adhesion. Our results presented above demonstrate that the presence of an assembled, methylated flagellar filament, but not the ability to move per se, contributes to the observed defect of Salmonella to invade epithelial cells. We note that our invasion assays report the number of bacteria that were successful in entering the eukaryotic cells. The assay thus reports two separate virulence mechanisms, i.e. successful invasion of epithelial cells is dependent on the Salmonella pathogenicity island-1 (spi-1) encoded injectisome and requires prior adhesion of the bacteria to the surface of eukaryotic cells, which is mediated through adhesion factors including pili, fimbriae and flagella.

Accordingly, we hypothesized that methylated flagella primarily facilitate bacterial adhesion to epithelial cells. We therefore investigated adhesion of Salmonella Typhimurium to MODE-K epithelial cells. In order to dissect flagella methylation-dependent adhesion from flagella methylation-dependent invasion of the epithelial cells, we employed Salmonella mutants deleted for spi-1, which renders the bacteria unable to invade epithelial cells in an injectisome-dependent manner. We found that adhesion of $\Delta s p i$ 1 Salmonella mutants to MODE-K epithelial cells was reduced up to $50 \%$ for strains deficient in flagellin methylation (Fig. 4c).

We next generated chromosomal substitution mutants of surface-exposed lysine residues in the $\mathrm{D} 2$ and $\mathrm{D} 3$ domains of FliC or FljB. As shown in Supplementary Fig. 6, the substitution of nine surface-exposed lysines with arginine in FliC (FliC-K9R) displayed an invasion defect similar to a $\Delta f l i B$ mutant. We note that the FliC-K9R mutation decreased motility to $70 \%$ of the WT, which might contribute to the more pronounced invasion defect of FliC-K9R compared to the $\Delta f l i B$ mutant. Replacing five surface-exposed lysine residues in the D3 domain of FliC with arginine (FliC-K5R) did not affect motility, but affected bacterial surface adhesion as described below (Supplementary Fig. 6a, c). We further found that a complete removal of the D3 domains of FliC (FliC $\Delta \mathrm{D} 3)$ or $\mathrm{FljB}(\mathrm{FljB} \Delta \mathrm{D} 3)$ did not affect motility (Supplementary Fig. 6d). Deleting the D3 domain also removes the majority of methylated lysines and, interestingly, FliC $\Delta \mathrm{D} 3$ and $\mathrm{FljB} \triangle \mathrm{D} 3$ strongly affected invasion of MODE-K epithelial cells (Supplementary Fig. 6e).

We further analyzed if the methylation-dependent invasion phenotype was eukaryotic cell-line specific (Supplementary Fig. 7). The human epithelial cell line $\mathrm{E} 12^{36}$ and murine intestinal epithelial cell line Cl11 mimic the native intestinal environment in vitro. Similar to the observed invasion rate of MODE-K cells, a $\Delta f l i B$ mutant strain displayed a two-fold decreased invasion rate of the human and murine epithelial cell lines compared with the WT. Similarly, in murine epithelial-like RenCa cells, the invasion rate of a $\triangle f l i B$ mutant was decreased. Invasion into the murine fibroblast cell lines NIH 3T3 and CT26, however, was independent of flagellin methylation, suggesting that the observed invasion phenotype is cell type-specific for epithelial-like cells.

Methylated flagella promote adhesion to hydrophobic surfaces. Our results described above demonstrate that methylated flagella promote bacterial adhesion to epithelial cells, e.g. through interaction with hydrophobic patches, surface-exposed proteinaceous receptors or glycostructures. However, we did not observe a significant flagella methylation-dependent effect on adhesion of Salmonella to various extracellular matrix proteins, nor to the oligosaccharide mannose, which has previously been shown to mediate adhesion of Salmonella and E. coli to eukaryotic cells 
a

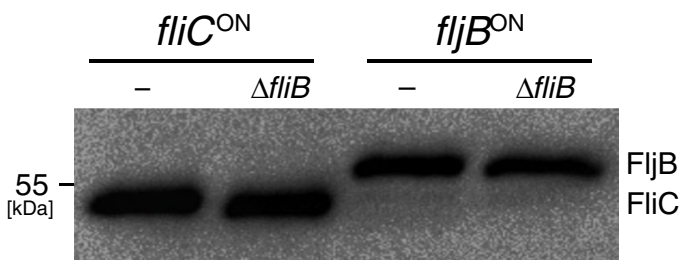

b
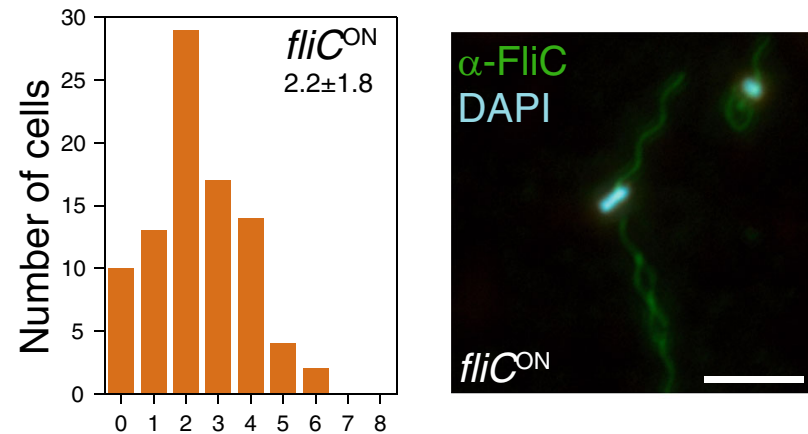

Flagella per cell
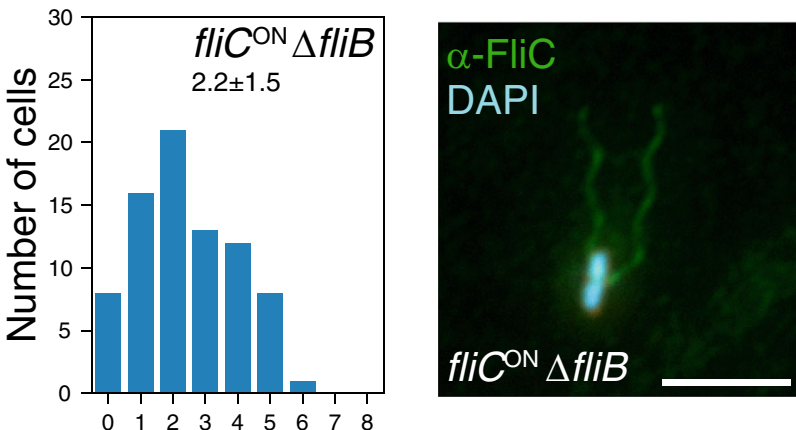

Flagella per cell

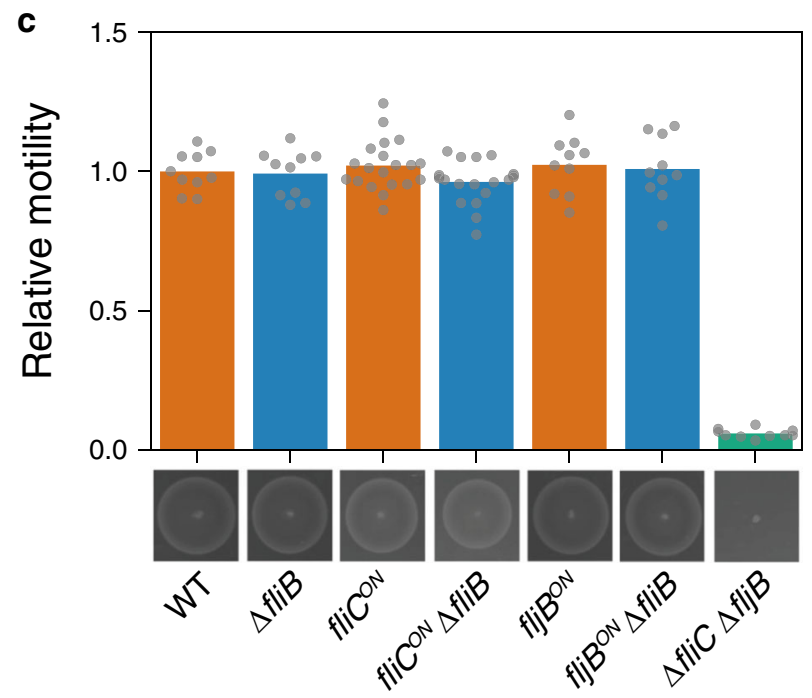

using type I fimbriae ${ }^{37-40}$ (Supplementary Fig. 8). We therefore reasoned that the addition of hydrophobic methyl groups to surface-exposed lysine residues (Fig. 2, Supplementary Fig. 9) might affect the hydrophobicity of the flagellar filament and through this mechanism promote bacterial adhesion to hydrophobic molecules present on the surface of epithelial cells. Consistently, the surface hydrophobicity (So) of purified FliC and FljB flagella was significantly reduced in the absence of lysine methylation (Fig. 5a, b).
Fig. 3 Effect of flagella methylation on swimming motility and flagellar assembly. a Secreted flagellins from culture supernatants of Salmonella Typhimurium strains locked in expression of either FliC ( fliCON) or FljB $(f l j \mathrm{ON}$ ). Secreted proteins were precipitated by addition of 10\% TCA and fractionated according to their molecular weight by SDS-PAGE. Immunoblotting was performed using $\alpha-$ FliC/FljB antibodies (1:5,000). A representative immunoblot is shown. The experiment has been repeated three times with similar results. $\mathbf{b}$ Left: Histograms of the number of flagella per cell of the WT (flicON) and an isogenic fliB mutant (flic ${ }^{\mathrm{ON}} \Delta$ fliB). $n=79$ bacteria for fliCON; $n=89$ bacteria for fliCON $\Delta$ fliB. Average flagella numbers were calculated by Gaussian non-linear regression analysis. Right: Representative flagella immunostaining images. Flagellar filaments were immunostained using $\alpha$-FliC primary (1:1000) and $\alpha$-rabbit conjugated AlexaFluor 488 secondary antibodies (1:1000; green). DNA was stained with DAPI (blue). Scale bar $=5 \mu \mathrm{m}$. c Motility phenotypes of the WT and fliB mutants were analyzed in soft-agar plates containing $0.3 \%$ agar and quantified after $4 \mathrm{~h}$ incubation at $37^{\circ} \mathrm{C}$. Bottom: representative motility plate. Top: The diameters of the motility swarm were measured and normalized to the control strain. The bar graphs represent the mean of $n=$ 10 biologically independent samples for the WT, $\Delta$ fliB, fljB ON, fljBON $\Delta f l i B$, and $\Delta$ fliC $\triangle$ fljB and $n=20$ biologically independent samples for fliCON and flicON $\Delta$ fliB. Replicates are shown as individual data points. Source data are provided as a Source Data file.

We next established an in vitro assay to investigate the possibility that the increased hydrophobicity of methylated flagella promotes bacterial adhesion to the hydrophobic plasma membrane (Fig. 5c). This assay is based on the binding of Salmonella to giant unilamellar vesicles (GUV) consisting of phosphatidylcholine (PC), the most abundant phospholipid in animal tissues. Notably, we observed a reduction in bacterial adhesion to GUVs consisting of PC for Salmonella Typhimurium strains deficient in flagellin methylation, but not for the non-flagellated $\Delta$ flgK mutants. In support, a mutant replacing several surface-exposed lysine residues with arginine in the D3 domain of FliC (FliC-K5R) displayed reduced adhesion to GUVs consisting of PC (Supplementary Fig. 6c). In addition, nonmotile, but flagellated bacteria $(\triangle \operatorname{mot} A B)$ were less adherent, which supports previous observations that actively rotating flagella are important for the initial interaction with surfaces before biofilm formation ${ }^{40}$ (Fig. 5c).

In order to validate the contribution of flagella methylation on adhesion of Salmonella to phospholipids, we tested adhesion of the WT and $\triangle f l i B$ mutants to phosphatidylglycerol vesicles. Phosphatidylglycerol (PG) is a minor lipid in higher eukaryotes ${ }^{41}$ and a negatively charged molecule as opposed to zwitterionic PC. We speculated that $\triangle f l i B$ mutants might display increased binding to GUVs consisting of PG due to exposed lysines in flagellin. As shown in Fig. 5d, we indeed observed significantly increased adhesion of $\Delta f l i B$ mutants with non-methylated flagella compared to the respective WT strains.

\section{Discussion}

Flagella-dependent motility is crucial for Salmonella pathogenesis by enabling directed movement towards host epithelial cells. However, flagella not only play a role in bacterial motility, but also in colonization, adhesion, and biofilm formation ${ }^{40,42,43}$. Concerning the role of flagella as an adhesion molecule, it is important to note that the flagellar filament is made of several thousand copies of a single protein, flagellin, which can mediate various interactions with surfaces.

Here, we describe a novel mechanism of flagella-dependent adhesion to surface-exposed hydrophobic molecules. This adhesion phenotype is facilitated by methylation of surface-exposed 
a

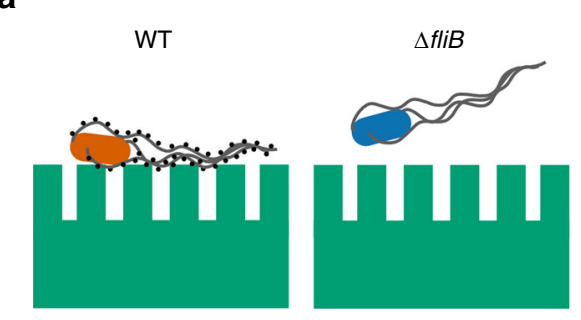

c

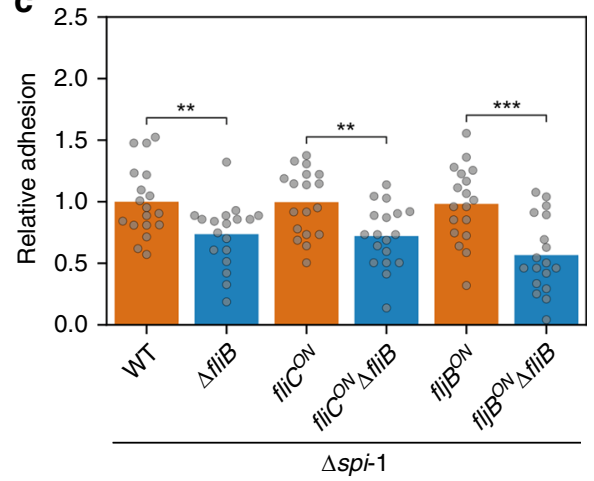

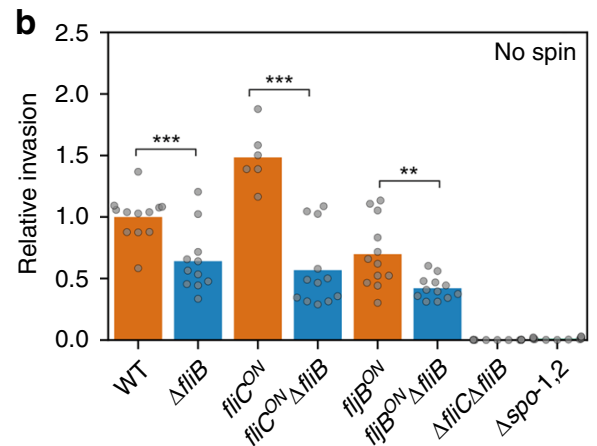

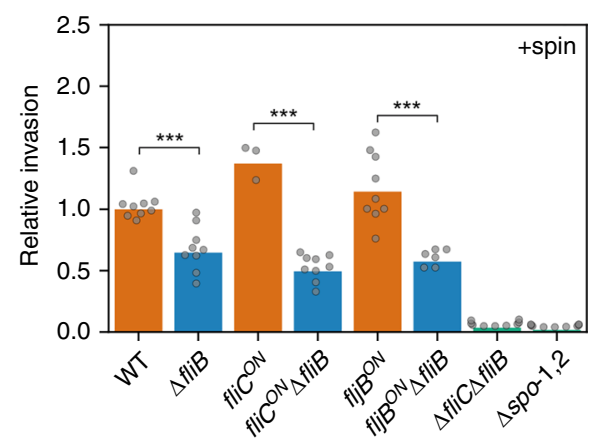

Fig. 4 Flagella methylation facilitates eukaryotic cell adhesion and invasion. a Schematic illustration of Salmonella Typhimurium adhesion to eukaryotic epithelial cells, which is facilitated by methylated flagella. $\mathbf{b}$ Invasion of MODE-K murine epithelial cells by Salmonella Typhimurium expressing methylated or non-methylated flagella. Reported are relative invasion rates of MODE-K epithelial cells for various flagellin methylation mutants without (top: no spin) or with forced contact of the bacteria by centrifugation (bottom: + spin). The bar graphs represent the mean of the reported data. Top: $n=12$ biologically independent samples for the WT, flic ${ }^{O N} \Delta f l i B, f l j B O N$, fljB ${ }^{O N} \Delta f l i B, \Delta f l i C \Delta f l j B$, and $\Delta s p i-1,2, n=11$ biologically independent samples for $\Delta$ fliB and $n=6$ biologically independent samples for flicON. Replicates are shown as individual data points and statistical significances were determined by a two-tailed

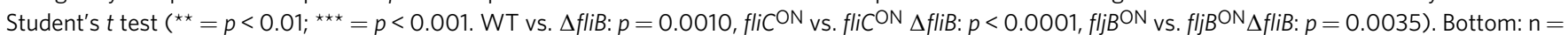

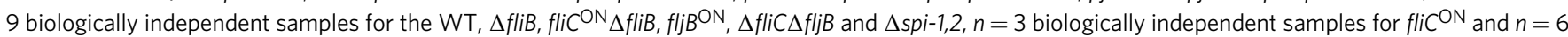
biologically independent samples for fljB ${ }^{O N} \triangle f l i B$. Replicates are shown as individual data points and statistical significances were determined by a two-tailed Student's $t$ test ${ }^{\star \star \star \star}=p<0.001$. WT vs. $\Delta$ fliB: $p=0.0002$, flic ${ }^{O N}$ vs. fliC ${ }^{O N} \Delta f l i B: p<0.0001$, fljB ${ }^{O N}$ vs. fljB $\left.{ }^{O N} \Delta f l i B: p=0.0004\right)$. c Adhesion of Salmonella Typhimurium to MODE-K epithelial cells is reduced in the absence of flagella methylation. Adhesion was monitored using Salmonella Typhimurium strains deleted for spi-1 in order to prevent invasion of the eukaryotic host cells. The bar graphs represent the mean of the reported relative invasion rate data normalized to the inoculum. $n=18$ biologically independent samples. Replicates are shown as individual data points and statistical significances were determined by a two-tailed Student's $t$ test ${ }^{\star \star}=p<0.01 ;{ }^{\star \star \star}=p<0.001$. WT vs. $\Delta$ fliB: $p=0.0069$, fliC ${ }^{O N}$ vs. flic ${ }^{O N} \Delta f l i B: p=0.0033$, flij $B^{O N}$ vs. $f l i B \mathrm{ON}_{\Delta}$ fliB: $\left.p=0.0003\right)$. Source data are provided as a Source Data file.

lysine residues of flagellin by the methylase FliB. Flagellin methylation was first described in Salmonella in 195924-26; however, the physiological relevance remained elusive. We demonstrate that FliB-mediated flagellin methylation is crucial for Salmonella pathogenesis in the mouse model and contributes significantly to adhesion and thus invasion of epithelial cells in vitro, but does neither affect swimming motility nor flagella assembly (Fig. 3). Analysis of the surface hydrophobicity of purified flagella revealed that methylation of the filament subunits increases the hydrophobicity of the outer surface of the flagellar filament, while the lumen of the flagellar filament seems not to be affected (Fig. 5a, b, Supplementary Fig. 9). We note that the preferential methylation of surface-exposed lysine residues suggests that the methylation of lysines depends on some structural feature of flagellin and might occur only after flagellin has at least partially been folded. Further, we found that a single flagellin molecule can contain up to 16 (FliC) or 18 (FljB) surface-exposed methylation sites. Since a flagellar filament is made up of up to 20,000 flagellin copies, the methylation of flagellin subunits might substantially increase the overall hydrophobicity of the flagellum. Consistently, we found that adhesion to the surface of epithelial host cells and phosphatidylcholine vesicles was enhanced by methylated flagella. In support, flagella have been recently implicated to mediate adhesion to abiotic surfaces through hydrophobic interactions ${ }^{44,45}$. We thus speculate that bacteria use flagella to explore the host cell surface as suggested previously ${ }^{46}$ and actively rotating flagella might be able to penetrate the lipid bilayer and interact with the fatty acids buried inside the plasma membrane. Increasing the surface hydrophobicity of the flagellar filament through methylation might improve those hydrophobic interactions for productive adhesion to eukaryotic host cells.

Flagellin Methylation Islands (FMI) and thus modifications of flagellins by methylation are common in Enterobacteriaceae ${ }^{19}$. In addition to Salmonella, many bacterial species including Yersinia, Enterobacter, Franconibacter, and Pantoea contain chromosomal FMI loci, which encode orthologues of FliB. Interestingly, a mutant of a FliB homolog in Aeromonas also reduced the adherence to HEp2-cells ${ }^{47}$. In summary, FliB-dependent methylation of flagella might represent a general mechanism facilitating adhesion to hydrophobic host cell surfaces in a broad range of bacterial species.

\section{Methods}

Ethics statement. All animal experiments were performed according to guidelines of the German Law for Animal Protection and with permission of the local ethics committee and the local authority LAVES (Niedersächsisches Landesamt für 
a

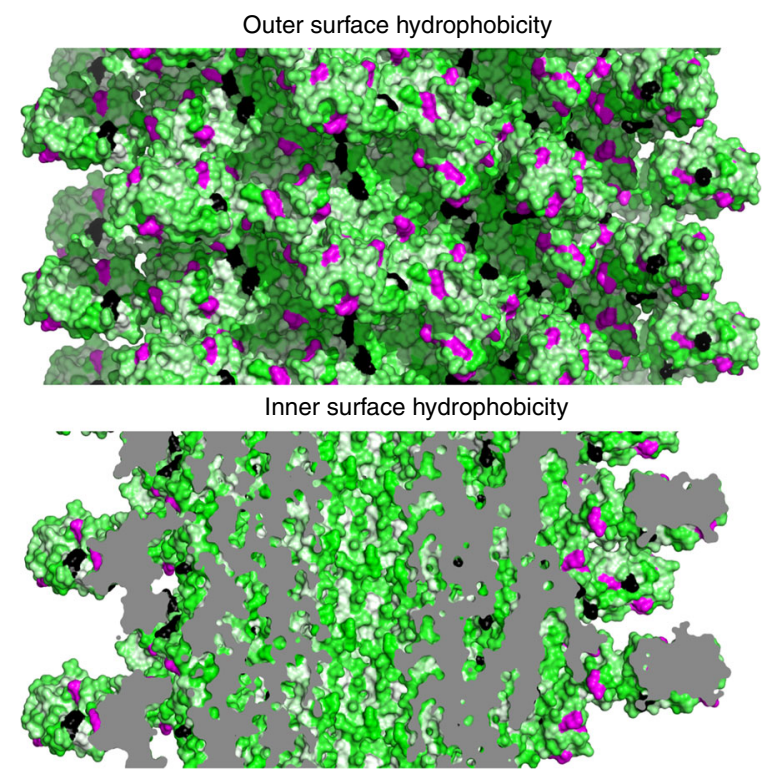

b

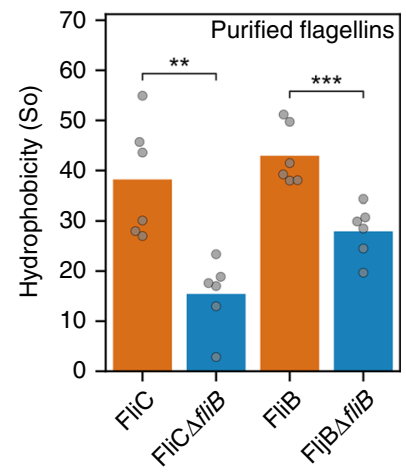

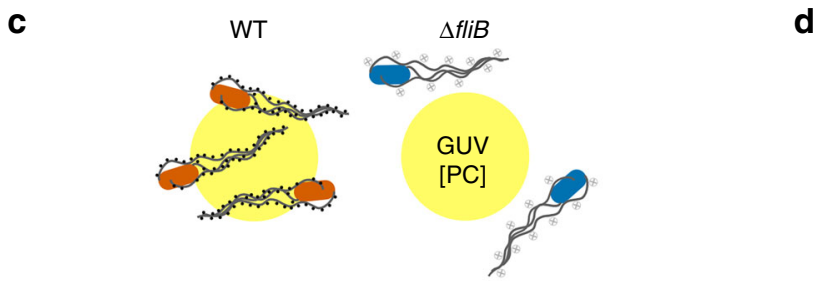

d
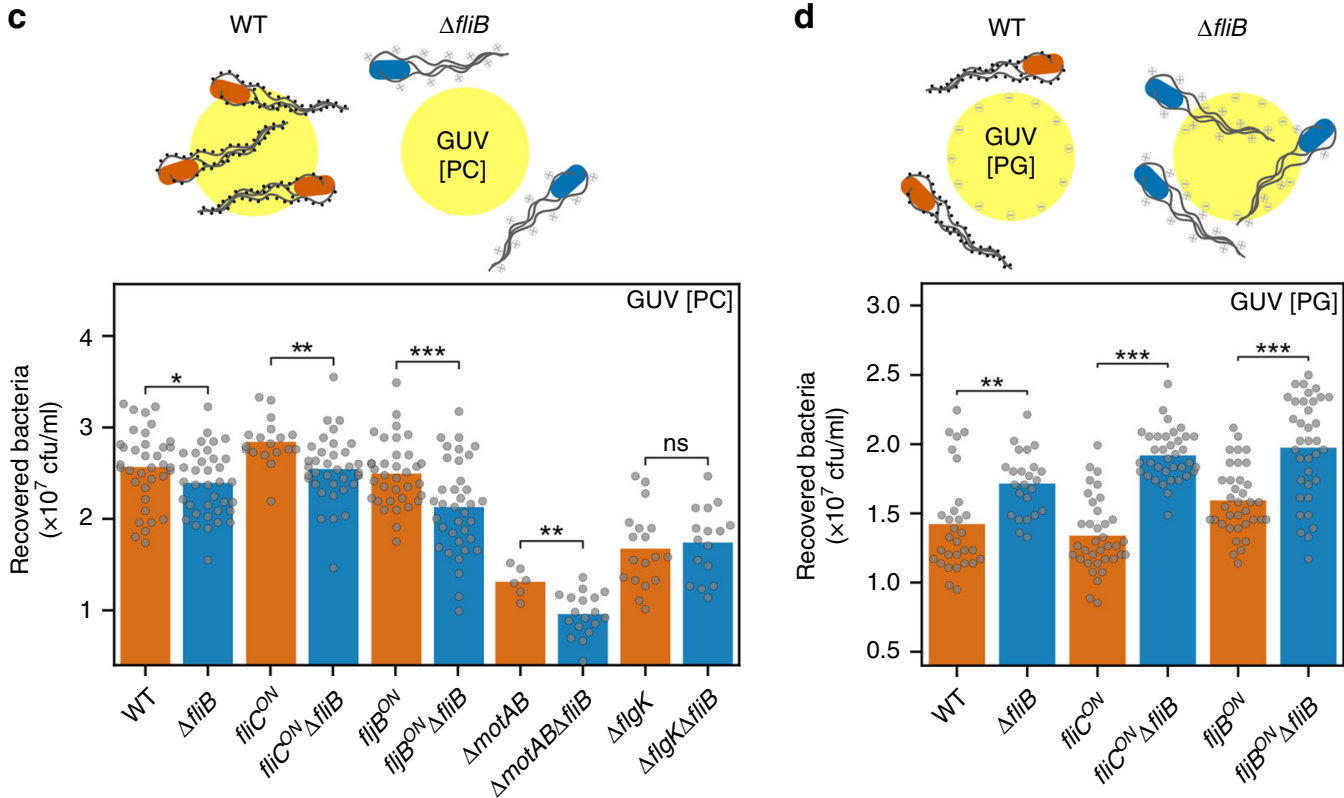

Fig. 5 Flagella methylation mediates adhesion to hydrophobic surfaces. a Methylation increases hydrophobicity of the flagellar filament outer surface. Surface hydrophobicity distribution of the outer (top) and inner (bottom) surface of the FliC flagellar filament ${ }^{70}$ according to the Eisenberg scale $^{71}$ (from green to white indicates increasing hydrophobicity) with methylation sites highlighted in magenta and non-methylated lysines in black. $\mathbf{b}$ Measured surface hydrophobicity (So) of methylated and non-methylated ( $\triangle$ fliB) flagellins using PRODAN on purified flagellar filaments. $n=6$ independent experiments. Replicates are shown as individual data points and statistical significances were determined by a two-tailed Student's $t$ test $\left({ }^{\star \star}=p<0.01\right.$; ${ }^{\star \star \star}=p<0.001$. FliC vs. FliC $\Delta f l i B: p=0.0020$, FljB vs. FljB $\Delta f l i B: p=0.0009$ ). c Adhesion of Salmonella Typhimurium to giant unilamellar vesicles (GUV) consisting of phosphatidylcholine (PC) from egg chicken is facilitated by the presence of methylated flagella. Top: schematic illustration of the adhesion of Salmonella to PC-GUVs, which is facilitated by methylated flagella. Bottom: Quantified adhesion of Salmonella mutants to PC-GUVs. WT, $\Delta f l i B$, fljB $O N \Delta f l i B, f l i C O N \Delta f l i B$ : $n=36 ; f l j B O N$ : $n=35 ;$ fliCON, $\Delta$ motAB $\Delta$ fliB, $\Delta$ flgK: $n=18 ; \Delta$ flgK $\Delta$ fliB: $n=16 ; \Delta$ motAB: $n=6$ biologically independent samples. Replicates are shown as individual data points and statistical significances were determined by a two-tailed Student's $t$ test $\left({ }^{\star}=p<0.05\right.$; ${ }^{\star \star}=p<0.01$; ${ }^{\star \star \star}=p<0.001$; ns $=$ not significant. WT vs. $\Delta$ fliB: $p=0.0437$, flic ${ }^{O N}$ vs. fli ${ }^{\mathrm{ON}} \Delta$ fliB: $p=0.0029$, flj $B^{\mathrm{ON}}$ vs. flj $\mathrm{ON}^{\mathrm{ON}} \mathrm{fliB}: p=0.0009, \Delta$ mot $A B$ vs. $\Delta$ mot $\left.A B \Delta f l i B: p=0.025\right)$. d Adhesion of Salmonella Typhimurium to GUVs consisting of phosphatidylglycerol (PG) is decreased by the presence of methylated flagella. Top: schematic illustration of the adhesion of Salmonella mutants to PG-GUVs. Bottom: Quantified adhesion of Salmonella mutants to PG-GUVs. The bar graphs represent the mean of the reported data. WT: $n=30 ; \Delta f l i B: n=24 ;$ fliCON flicON $\triangle f l i B$, fljBON and fliB ${ }^{O N} \Delta f l i B: n=36$ biologically independent samples. Replicates are shown as individual data points and statistical significances were determined by a two-tailed Student's $t$ test ${ }^{\star \star *}=p<0.01$; ${ }^{\star \star \star}=p<0.001$. WT vs. $\Delta f$ fliB: $p=0.0010$, fliCON vs. flic ${ }^{O N} \Delta f l i B: p<0.0001$, fljBON vs. fljBON $\left.\triangle f l i B: p<0.0001\right)$. The bar graphs represent the mean of the reported data. Source data are provided as a Source Data file. 
Verbraucherschutz und Lebensmittelsicherheit) under permission number 33.1942502-04-13/1191. Mice were housed in individually-ventilated cages with free access to autoclaved water and chow.

Strains, media, and bacterial growth. All bacterial strains used in this study are listed in Supplementary Table 3 and were derived from Salmonella enterica serovar Typhimurium strain SL1344. Bacteria were grown in lysogeny broth (LB) at $37^{\circ} \mathrm{C}$ and growth was measured by optical density at $600 \mathrm{~nm}$. For transductional crosses the generalized transducing phage P22 HT105/1 int-201 was used ${ }^{48}$. Gene deletions or replacements were produced using $\lambda$-RED mediated homologous recombination $^{49}$. All bacterial strains are available upon request.

Cloning and purification of FljB for structural analysis. The truncated gene $f l j B$ encoding for the protein residues 55-462 was amplified from Salmonella Typhimurium SL1344 by standard PCR method and cloned into the expression vector pET28a $(+)$ using the restriction sites NheI and XhoI to generate a N-terminal Histagged protein. The plasmid contained a A190V mutation as determined by sequencing. Standard protocols were performed for expression of His-tagged $\mathrm{FljB}_{55-462}$ in BL21(DE3). The protein was purified from the soluble fraction using HisTrap HP and Superdex 75 columns (GE Healthcare) and eluted in the buffer $50 \mathrm{mM}$ HEPES (pH 7.4), $150 \mathrm{mM} \mathrm{NaCl}$

Crystallization and data collection. $\mathrm{FljB}_{55-462}$ was concentrated to $12-15 \mathrm{mg} \mathrm{mL}^{-1}$ and crystals were grown at $18^{\circ} \mathrm{C}$ by hanging drop vapour diffusion against $0.1 \mathrm{M}$ Tris ( $\mathrm{pH}$ 8.5), 20\% (w/v) PEG4000, 24\% (v/v) isopropanol. Diffraction data were collected using crystals flash-frozen in crystallization buffer. Measurements were carried out at the beamLine BL14.1 at the Helmholtz-Zentrum Berlin synchrotron Bessy $\mathrm{II}^{50,51}$, using a wavelength of $0.918 \AA$ and at $100 \mathrm{~K}$, which allowed us to obtain a data set at $2.00 \AA$ resolution. Crystals belong to space group C2, with one FljB molecule in the asymmetric unit (solvent content $51.6 \%$ ). Indexing, integration, merging, and scaling were done using the program $\mathrm{XDS}^{52}$.

Crystal structure determination. The structure was phased by molecular replacement with Phaser version 2.5.253, using the structure of the F41 fragment of FliC flagellin as search model (PDB $1 \mathrm{IO}^{18}$ ). Cycles of manual building and refinement using $\operatorname{Coot}^{54}$ and CNS version $1.3^{55}$ led to the final structure, which includes residues 55-459 of FljB with the mutation A190V and the residue S54 present in the crystallized construct. 299 water molecules were also placed. Structural comparison between $\mathrm{FljB}$ and $\mathrm{FliC}$ was performed using the server PDBeFold v2.5956. Molecular structure figures were generated using UCSF Chimera 1.13.157 (developed by the Resource for Biocomputing, Visualization, and Informatics at the University of California, San Francisco, with support from NIH P41-GM103311) and PyMol 2.2.3 (Schroedinger, LLC (2018). The amino acid alignment shown in Fig. 1d was generated using the server ESPript (http://espript.ibcp.fr) ${ }^{58}$

Filament purification for mass spectrometry analysis. Flagellar hook-basalbodies with attached filaments of strains locked in either $f l i C^{\mathrm{ON}}$ or $f l j B^{\mathrm{ON}}$ and additionally harboring a $\Delta f l i B$ mutation were purified as described ${ }^{59}$ with minor modifications. Briefly, $500 \mathrm{~mL}$ logarithmically grown cultures were pelleted and resuspended in ice-cold sucrose solution ( $0.5 \mathrm{M}$ sucrose, $0.1 \mathrm{M}$ Tris-HCl, pH 8$) .3 \mathrm{~mL}$ $10 \mathrm{mg} \mathrm{mL}^{-1}$ lysozyme and $3 \mathrm{~mL} 0.1 \mathrm{M}$ EDTA were added drop wise into the samples and incubated at $4{ }^{\circ} \mathrm{C}$ for $30 \mathrm{~min}$. Next, $3 \mathrm{~mL} 10 \%$ Triton X-100 and $3 \mathrm{~mL}$ $0.1 \mathrm{M} \mathrm{MgSO} 4$ were added followed by overnight incubation at $4^{\circ} \mathrm{C}$. After lysis, $3 \mathrm{~mL} 0.1 \mathrm{M}$ EDTA, $\mathrm{pH} 11$ was added and samples were centrifuged at $17,000 \times g$ at $4{ }^{\circ} \mathrm{C}$ for $20 \mathrm{~min}$. The supernatant was adjusted with $5 \mathrm{M} \mathrm{NaOH}$ to $\mathrm{pH} 11$ and pelleted again. Hook-basal-bodies with attached filaments were subsequently collected by ultracentrifugation at $100,000 \times g$ at $4{ }^{\circ} \mathrm{C}$ for $1 \mathrm{~h}$. The pellet was resuspended in buffer $(10 \%$ sucrose, $0.1 \mathrm{M} \mathrm{KCl}, 0.1 \%$ Triton X-100, $\mathrm{pH} 11)$ and centrifuged at $17,000 \times g$ at $4{ }^{\circ} \mathrm{C}$ for 20 min. Finally, purified flagellar filaments were washed in TET buffer $(10 \mathrm{mM}$ Tris- $\mathrm{HCl}, 5 \mathrm{mM}$ EDTA, $\mathrm{pH} 8,0.1 \%$ Triton $\mathrm{X}-100)$, air-dried and re-suspended in $200 \mu \mathrm{l}$ TE buffer (10 mM Tris-HCl, $5 \mathrm{mM}$ EDTA, pH 8). Samples were fractionated on NativePAGE 3-12\% Bis-Tris gels (Invitrogen) and proteins were stained using Coomassie blue. Target bands were cut and prepared for mass spectrometry as detailed below.

Mass spectrometry sample preparation. FliC and $\mathrm{FljB}$ purified from the WT and a $\triangle f l i B$ mutant were separated using SDS-PAGE. The corresponding bands were cut from the gel and each was cut into $1 \times 1 \mathrm{~mm}$ pieces. An in-gel digestion was performed. In order to destain the gel pieces, a $50 \mathrm{mM}$ ammonium bicarbonate $(\mathrm{AmBiCa})$ in $50 \%$ acetonitrile (ACN) solution was added and incubated $30 \mathrm{~min}$ at room temperature to dehydrate the gel. After removal of the supernatant, $50 \mathrm{mM}$ AmBiCa was added and incubated for $30 \mathrm{~min}$ at room temperature to rehydrate the pieces. This step was repeated two times. Disulfide bonds were reduced using $10 \mathrm{mM}$ DTT in $50 \mathrm{mM} \mathrm{AmBiCa}$ for $30 \mathrm{~min}$ at $56^{\circ} \mathrm{C}$. After cooling to room temperature and removal of the supernatant, the reduced cysteines were alkylated using $55 \mathrm{mM}$ iodoacetamide in $50 \mathrm{mM} \mathrm{AmBiCa}$ for $30 \mathrm{~min}$ at room temperature in the dark. After removal of the supernatant the gel pieces were dried in vacuo. Ice cold $50 \mathrm{mM}$ AmBiCa in $10 \% \mathrm{ACN}$ containing $12.5 \mathrm{ng} \mu \mathrm{L}^{-1}$ trypsin was added and digested overnight. Peptides were extracted by transferring the supernatant to a fresh collection tube and adding $50 \mathrm{mM} \mathrm{AmBiCa}$ in $10 \% \mathrm{ACN}$ to the gel pieces and transferring the second supernatant into the same collection tube. Peptides were dried in vacuo and stored at $-20^{\circ} \mathrm{C}$. Before measuring the peptides were reconstituted in $10 \mu \mathrm{L} 0.1 \%$ formic acid (FA) and $1 \mu \mathrm{L}$ was injected for measurement. All chemicals were purchased from Sigma-Aldrich. Trypsin was purchased from Promega.

Mass spectrometry analysis. Peptides were measured on a tandem mass spectrometer (Fusion, Thermo Fisher Scientific) coupled to a nano UPLC system (Ultimate 3000 RSLCnano, Thermo Fisher Scientific) with a nano-spray source. Peptides were trapped on a C18 reversed-phase trap column $(2 \mathrm{~cm} \times 75 \mu \mathrm{m} \mathrm{ID}$; Acclaim PepMap trap column packed with $3 \mu \mathrm{m}$ beads, Thermo Fisher Scientific) and separated on a $25 \mathrm{~cm} \mathrm{C18} \mathrm{reversed-phase} \mathrm{analytical} \mathrm{column}(25 \mathrm{~cm} \times 75 \mu \mathrm{m}$ ID, Acclaim PepMap, $3 \mu \mathrm{m}$ beads, Thermo Fisher Scientific). The column temperature was kept constant at $45^{\circ} \mathrm{C}$. Peptides were separated using a 2-step gradient starting with $3 \%$ buffer B $(0.1 \%$ FA in ACN) and $97 \%$ buffer A $(0.1 \%$ FA in $\mathrm{H}_{2} \mathrm{O}$ ) with a steady increase to $28 \%$ buffer B over $20 \mathrm{~min}$ and a second increase to $35 \%$ over 5 min with a subsequent ramping to $90 \%$ buffer B for 10 min followed by a $20 \mathrm{~min}$ equilibration to $3 \%$ buffer $\mathrm{B}$ at a constant flow rate of $300 \mathrm{~nL} \mathrm{~min}^{-1}$. Eluting peptides were injected directly into the mass spectrometer. Data were acquired in positive ion mode using data dependent acquisition (DDA) with a precursor ion scan resolution of $1.2 \times 10^{5}$ at $200 \mathrm{~m} \cdot \mathrm{z}^{-1}$ in a range of $300-1500 \mathrm{~m} \cdot \mathrm{z}^{-1}$ with an automatic gain control (AGC) target of $2 \times 10^{5}$ and a maximum injection time of $50 \mathrm{~ms}$. Peptides were selected for fragmentation using the 'TopSpeed' method with a threshold of 5000 intensity and a dynamic exclusion time of $30 \mathrm{~s}$. Peptides were fragmented using higher-energy collision dissociation (HCD) in the C-Trap and fragment spectra were detected in the ion trap. Fragment spectra were recorded using the "Rapid" setting with a maximum injection time of $35 \mathrm{~ms}$ and an AGC target of $1 \times 10^{4}$ with the first mass set at $110 \mathrm{~m} \cdot \mathrm{z}^{-1}$.

Mass spectrometry data analysis. Data were analyzed using the ProteomeDiscoverer 2.0 (Thermo Fisher Scientific) software. Spectra were identified using the Sequest HT search engine with precursor mass tolerance set to $10 \mathrm{ppm}$ and the fragment mass tolerance set to $0.5 \mathrm{Da}$. Carbamidomethylation on cysteine was set as fixed modification and oxidation on methionine, acetylation on protein $\mathrm{N}$ terminus as well as mono-, di- and tri-methylation on lysine were set as variable modifications. Trypsin was set as enzyme and three missed cleavages were allowed with a minimum peptide length of six amino acids. Spectra were searched against a Salmonella Typhimurium FASTA database obtained from UniProt in June 2016 containing 1821 entries and a contaminant database containing 298 entries. Sequence coverage maps were created using PatterLab for proteomics $4.0^{60}$.

Protein secretion assay. Bacterial strains were grown over night in LB medium at $37^{\circ} \mathrm{C}$, diluted 1:100 into fresh medium and grown to mid-logarithmic phase. $1.5 \mathrm{~mL}$ samples of the culture supernatant were collected and precipitated by addition of $10 \%$ TCA and centrifuged for $1 \mathrm{~h}$ at $4{ }^{\circ} \mathrm{C}$. The protein pellet was washed twice with acetone and air dried. Samples were adjusted to 200 OD units and fractionated under denaturizing conditions using SDS-PAGE and immunoblotting was performed using primary a-FliC (Difco, catalog number 228241 Salmonella $\mathrm{H}$ Antiserum I. 1:5,000 in TBS-T) or a-FljB (Difco, catalog number 224741 Salmonella $\mathrm{H}$ Antiserum Single Factor 2, 1:5,000 in TBS-T) antibodies and detection was performed using secondary $a$-rabbit antibodies conjugated to horseradish peroxidase (Bio-Rad Immun-Star Goat Anti-Rabbit (GAR)-HRP Conjugate, catalog number 170-5046, 1:20,000 in TBS-T).

Motility assay and immunostaining of flagellar filaments. Swimming motility was analyzed in semi-solid agar plates containing $0.3 \%(\mathrm{w} / \mathrm{v})$ agar. Single colonies were inoculated into the agar, and the plates were incubated at $37^{\circ} \mathrm{C}$ for $4 \mathrm{~h}$. Images were acquired by scanning the plates and the diameter of the swimming halos were determined using NIH ImageJ $1.48 \mathrm{v}$ and normalized to the WT control of the same plate. For immunostaining of flagellar filaments, logarithmically grown cells locked in expression of either $\mathrm{FliC}^{\mathrm{ON}}$ or $\mathrm{Flj}_{\mathrm{B}} \mathrm{ON}$ were fixed by addition of $2 \%$ formaldehyde and $0.2 \%$ glutaraldehyde for $10 \mathrm{~min}$ and immobilized on a poly-Llysine coated coverslip. Flagellar filaments were immunostained using polyclonal aFliC (Difco, catalog number 228241 Salmonella $\mathrm{H}$ Antiserum I, 1:1,000 in 2\% BSA/ PBS) or $\alpha$-FljB (Difco, catalog number 224741 Salmonella H Antiserum Single Factor 2, 1:1,000 in 2\% BSA/PBS) and secondary $\alpha$-rabbit Alexa-Fluor488 (Invitrogen, catalog number A-11094, 1:1,000 in PBS). DNA was stained using DAPI (Sigma-Aldrich). Images were collected and processed as described before ${ }^{28,61}$.

Mouse infection studies. Seven-week-old C57BL/6 mice (Janvier) were pretreated with $100 \mathrm{mg} \mathrm{mL}^{-1}$ streptomycin. Mice were co-infected intragastrically with $10^{7}$ colony forming units (CFU) each of two Salmonella Typhimurium strains that contained a different antibiotic resistance cassette. Small intestine, cecum and colon were isolated 2 days post-infection and plated on respective antibiotics resistance plates. The CFU were counted and reported as CFU per gram tissue. Competitive indices $(\mathrm{CI})$ were calculated by normalizing the percentage of each strain to the inoculum and the challenge strain. 
Invasion and adhesion assays. The murine epithelial cell lines MODE- $\mathrm{K}^{62}$ and Cl11, the murine epithelial-like cell line Renca (CRL-2947), the human epithelial cell line HT29-MTX-E12 (E12) ${ }^{36}$, the mouse fibroblast cell lines NIH-3T3 (CRL1658) and CT26 (CRL-2638) were used for invasion assays. The immortalization and characterization of the muGob (Cl11) cells will be described elsewhere (Truschel et al., in preparation). Briefly, murine intestinal organoids were plated and infected with different lentiviruses encoding the CI-SCREEN gene library ${ }^{63}$. After transduction, the clonal cell line muGob (Cl11) was established, which has integrated the following recombinant genes of the CI-SCREEN library: Id1, Id2, Id3, Myc, Fos, E7, Core, Rex (Zfp42). The muGob (Cl11) cell line was cultivated on fibronectin/collagen-coated (InSCREENeX GmbH, Germany) well plates in a humidified atmosphere with $5 \% \mathrm{CO}_{2}$ at $37^{\circ} \mathrm{C}$ in a defined muGob medium (InSCREENeX GmbH, Germany). $2.5 \times 10^{5}$ cells per $\mathrm{mL}$ were seeded in 24 -well plates. For invasion of MODE-K epithelial cells, $5 \times 10^{5}$ cells per $\mathrm{mL}$ were seeded in 24-well plates and incubated overnight in a humidified atmosphere with $5 \% \mathrm{CO}_{2}$ at $37^{\circ} \mathrm{C}$. Salmonella strains were grown to mid-log phase, diluted in binding buffer (DMEM, $1 \%$ non-essential amino acids, $10 \%$ heat-inactivated FCS, $0.4 \%$ BSA, $20 \mathrm{mM}$ HEPES $\mathrm{pH}$ 7.5) and added at a MOI of 10. The contact of the bacteria with the epithelial cells was forced by centrifugation for $5 \mathrm{~min}$ at $500 \times g$ and the infection was performed for $1 \mathrm{~h}$ in a humidified atmosphere with $5 \% \mathrm{CO}_{2}$ at $37^{\circ} \mathrm{C}$. After washing twice with $1 \times$ PBS, external bacteria were killed by addition of $100 \mu \mathrm{g} \cdot \mathrm{mL}^{-1}$ gentamycin for $1 \mathrm{~h}$ and cells were lysed using $1 \%$ Triton X-100. Serial dilutions of the lysate were plated to calculate the $\mathrm{CFU}$ per $\mathrm{mL}$. All values were normalized to the control strain and invasion rates were calculated relative to the inoculum. For analysis of Salmonella Typhimurium adhesion to MODE-K epithelial cells, a modified assay was performed using Salmonella strains lacking spi-1 to prevent injectisome-dependent invasion. Bacteria were added to MODE-K epithelial cells at a MOI of 10 and incubated for $1 \mathrm{~h}$. Afterwards, the MODE-K cells were washed extensively to remove unbound bacteria and Salmonella CFU per mL were determined as described above without addition of gentamycin to kill external bacteria.

RNA isolation and quantitative real-time PCR. Strains were grown under agitating growth conditions in LB medium and total RNA isolation was performed using the RNeasy Mini kit (Qiagen). For removal of genomic DNA, RNA was treated with DNase using the TURBO DNA-free kit (Ambion). Reverse transcription and quantitative real-time PCRs (qRT-PCR) were performed using the SensiFast SYBR No-ROX One Step kit (Bioline) in a Rotor-Gene Q Lightcycler (Qiagen). Relative changes in mRNA levels were analyzed according to Pfaffl ${ }^{64}$ and normalized against the transcription levels of the reference genes gyrB, gmk and $r p o D^{28}$.

ECM adhesion assays. For ECM protein adhesion assays, a 96-well plate precoated with a variety of ECM proteins was used (EMD Millipore; Collagen I, II, IV, Fibronectin, Laminin, Tenascin, Vitronectin). Wells were rehydrated according to the user's manual and $5 \cdot 10^{7}$ cells per $\mathrm{mL}$ were added. After incubation for $1 \mathrm{~h}$ at $37^{\circ} \mathrm{C}$, wells were washed extensively and $1 \%$ Triton X-100 was added. CFU per mL were calculated after plating of serial dilutions and normalized to the inoculum and a BSA control.

Mannose binding assay. Binding to mannose was determined as described before ${ }^{65}$ with minor modifications. A black 96 -well plate was coated with BSA or mannose-BSA (20 $\mu \mathrm{g} \mathrm{mL}^{-1}$ in $50 \mathrm{mM}$ bicarbonate buffer $\left.\mathrm{pH} 9.5\right)$ for $2 \mathrm{~h}$ at $37^{\circ} \mathrm{C}$, followed by blocking with BSA $\left(10 \mathrm{mg} \mathrm{mL}^{-1}\right)$ for $1 \mathrm{~h}$ at $37^{\circ} \mathrm{C}$. Adjusted bacterial cultures $\left(\mathrm{OD}_{600} 0.6\right)$ harboring the constitutive fluorescent plasmid $\mathrm{pFU} 228-\mathrm{P}_{\text {gapdh }}{ }^{-}$ mCherry were added to the wells to facilitate binding. After $1 \mathrm{~h}$ incubation at $37^{\circ} \mathrm{C}$, wells were washed with $1 \times \mathrm{PBS}$ and fluorescence was measured using a Tecan plate reader (excitation $560 \mathrm{~nm}$; emission $630 \mathrm{~nm}$ ). Fluorescence relative to the binding to BSA was calculated from three technical replicates and the type-I fimbriaeinducible strain $\mathrm{P}_{\text {tet }}-f i m A-F$ served as positive control.

Filament isolation for surface hydrophobicity measurements. Bacterial cultures were grown in $\mathrm{LB}$ media at $37^{\circ} \mathrm{C}$ for $16 \mathrm{~h}$ in an orbital shaker incubator (Infors HT) at $80 \mathrm{rpm}$. Cells were harvest by centrifugation at $2000 \times g$ for $20 \mathrm{~min}$. Cell pellets were re-suspended in TBS buffer $\mathrm{pH} 7.4$ at $4{ }^{\circ} \mathrm{C}$. The flagellar filaments were sheared-off using a magnetic stirrer at $500 \mathrm{rpm}$ for $1 \mathrm{~h}$, followed by centrifugation at $4000 \times g$ for $30 \mathrm{~min}$. Supernatants were collected and ammonium sulfate was slowly added while stirring to achieve two-thirds saturation. After overnight incubation, the flagella were harvest by centrifugation at 15,000 $\times g$ for $20 \mathrm{~min}$ and pellet was re-suspended in TBS buffer at $\mathrm{pH}$ 7.4. The quality of the purified flagella was checked by SDS-PAGE and transmission electron microscopy of negatively stained samples (microscope Talos L120C, Thermo Fisher Scientific).

Hydrophobicity determination. Protein surface hydrophobicity was measured according to a modification of the method of Kato and Nakai ${ }^{66}$ using PRODAN ${ }^{67}$. A stock solution of $1 \mathrm{mM}$ PRODAN (prepared in DMSO) was used, $8 \mu \mathrm{L}$ was added to successive samples containing $1 \mathrm{~mL}$ of diluted flagella in $20 \mathrm{mM}$ HEPES ( $\mathrm{pH}$ 7.4), $150 \mathrm{mM} \mathrm{NaCl}$. After homogenization by pipetting, the samples were incubated $10 \mathrm{~min}$ in the dark and the relative fluorescence intensity was measured.
All fluorescence measurements were made with a Cary Eclipse (Varian now Agilent) spectrofluorometer. Excitation and emission wavelengths were $365 \mathrm{~nm}$ and $465 \mathrm{~nm}$, the slit widths were 5 and $5 \mathrm{~nm}$. For standardization, BSA was used. Surface hydrophobicity (So) values were determined using at least duplicate analyses. Five measures per sample repeated three times were performed and the mean was used.

Bacterial adhesion to liposomes. Giant unilamellar vesicles (GUV) for PC (egg chicken (Sigma-Aldrich) or 1-palmitoyl-2-oleoyle-glycero-3-phosphocholine) and PG (1-palmitoyl-2-oleoyl-sn-glycero-3-phospho-(1'-rac-glycerol)) were prepared according to the polyvinyl alcohol (PVA)-assisted swelling method ${ }^{68}$. Gold-coated glass slides were obtained by thermal evaporation under vacuum (Evaporator Edwards model Auto 306, $\left.0.01 \mathrm{~nm} \mathrm{~s}^{-1},(2-3) \times 10^{-6} \mathrm{mbar}\right)$. A gold layer of $10 \pm$ $1 \mathrm{~nm}$ was deposited on top of a chromium adhesion layer of $1 \pm 0.5 \mathrm{~nm}$. Prior to GUV formation in HEPES buffered saline solution (HEPES $20 \mathrm{mM} \mathrm{pH} 7.4, \mathrm{NaCl}$ $150 \mathrm{mM}$ ), 1,2-distearoyl-sn-glycero-3-phosphoethanolamine-N-[PDP(polyethylene glycol)-2000] (DSPE-PEG-PDP) (Sigma-Aldrich) was mixed with L-aphosphatidylcholine from egg chicken (Sigma-Aldrich) at a $3 \%$ mass ratio that allows a direct covalent coupling of GUV onto gold surfaces. For the bacterial adhesion assay, a $5 \mu \mathrm{g} \mathrm{mL}^{-1}$ GUV solution was deposited onto a gold-coated glass substrate and incubated $1 \mathrm{~h}$ for immobilization. Then, the surface was gently rinsed with buffer to remove non-immobilized liposomes. Subsequently bacterial culture at $10^{8} \mathrm{CFU}$ per $\mathrm{mL}$ resuspended in HEPES buffer was carefully deposit on the surface and incubated for $1 \mathrm{~h}$. Non-adherent bacteria were removed by washing with buffer. Finally, the adherent bacteria were detached by pipetting several times directly onto the immobilized liposomes with PBS pH 7.4. The collected samples were serially diluted and plated on LB agar for viable bacterial counts.

Statistical analysis. Data were analyzed using GraphPad Prism $6.0 \mathrm{~h}$ and statannot 0.1 .0 , a Python package for statistical annotations and analyses (https:// github.com/webermarcolivier/statannot). Two-tailed Student's $t$-tests were used as appropriate. The $p$ values $<0.05$ were considered significant.

Reporting summary. Further information on research design is available in the Nature Research Reporting Summary linked to this article.

\section{Data availability}

The authors declare that all data supporting the findings of this study are available within the paper and its supplementary information files. Full scans of the gels and blots are available in Supplementary Fig. 10. The source data underlying Figs. 2b, 3a-c, $4 b$, c , and $5 \mathrm{~b}-\mathrm{d}$ and Supplementary Figs. $4 \mathrm{a}-\mathrm{c}, 5,6 \mathrm{a}-\mathrm{e}, 7 \mathrm{a}-\mathrm{e}$ and $8 \mathrm{a}, \mathrm{b}$ are provided as a Source Data file. Methylation data as well as corresponding mass spectrometry proteomics data have been deposited to the ProteomeXchange Consortium via the PRIDE ${ }^{69}$ partner repository with the dataset identifier PXD017935 [https://doi.org/10.6019/PXD017935]. The coordinates of the flagellin FljB have been deposited in the worldwide Protein Data Bank (wwPDB) under accession number 6RGV [https://doi.org/10.2210/pdb6rgv/pdb]

Received: 9 September 2019; Accepted: 13 March 2020;

Published online: 24 April 2020

\section{References}

1. Adler, J. \& Templeton, B. The effect of environmental conditions on the motility of Escherichia coli. J. Gen. Microbiol 46, 175-184 (1967).

2. Duan, Q., Zhou, M., Zhu, L. \& Zhu, G. Flagella and bacterial pathogenicity. J. Basic Microbiol 53, 1-8 (2013).

3. Chaban, B., Hughes, H. V. \& Beeby, M. The flagellum in bacterial pathogens: For motility and a whole lot more. Semin. Cell Dev. Biol. 46, 91-103 (2015).

4. Rossez, Y., Wolfson, E. B., Holmes, A., Gally, D. L. \& Holden, N. J. Bacterial flagella: twist and stick, or dodge across the kingdoms. PLoS Pathog. 11, e1004483 (2015)

5. Rossi, C., Cazzola, H., Holden, N. J. \& Rossez, Y. in Health Consequences of Microbial Interactions with Hydrocarbons, Oils, and Lipids 1-21 (Springer International Publishing, Cham, 2019).

6. Tawk, C. et al. Stress-induced host membrane remodeling protects from infection by non-motile bacterial pathogens. EMBO J 37, E98529 (2018).

7. Lillehoj, E. P., Kim, B. T. \& Kim, K. C. Identification of Pseudomonas aeruginosa flagellin as an adhesin for Mucl mucin. Am. J. Physiol. Lung Cell Mol. Physiol. 282, L751-L756 (2002).

8. Girón, J. A., Torres, A. G., Freer, E. \& Kaper, J. B. The flagella of enteropathogenic Escherichia coli mediate adherence to epithelial cells. Mol. Microbiol 44, 361-379 (2002).

9. Roy, K. et al. Enterotoxigenic Escherichia coli EtpA mediates adhesion between flagella and host cells. Nature 457, 594-598 (2009). 
10. Crawford, R. W., Reeve, K. E. \& Gunn, J. S. Flagellated but not hyperfimbriated Salmonella enterica serovar Typhimurium attaches to and forms biofilms on cholesterol-coated surfaces. J. Bacteriol. 192, 2981-2990 (2010).

11. Rossez, Y. et al. Flagella interact with ionic plant lipids to mediate adherence of pathogenic Escherichia coli to fresh produce plants. Environ. Microbiol 16, 2181-2195 (2014).

12. Feldman, M. et al. Role of flagella in pathogenesis of Pseudomonas aeruginosa pulmonary infection. Infect. Immun. 66, 43-51 (1998).

13. Adamo, R., Sokol, S., Soong, G., Gomez, M. I. \& Prince, A. Pseudomonas aeruginosa flagella activate airway epithelial cells through asialoGM1 and tolllike receptor 2 as well as toll-like receptor 5. Am. J. Respir. Cell Mol. Biol. 30, 627-634 (2004).

14. Berg, H. C. The rotary motor of bacterial flagella. Annu Rev. Biochem 72, 19-54 (2003).

15. Renault, T. T. et al. Bacterial flagella grow through an injection-diffusion mechanism. Elife 6, e23136 (2017).

16. Lederberg, J. \& Iino, T. Phase variation in Salmonella. Genetics 41, 743 (1956).

17. Horstmann, J. A. et al. Flagellin phase-dependent swimming on epithelial cell surfaces contributes to productive Salmonella gut colonisation. Cell Microbiol 19, e12739 (2017).

18. Samatey, F. A. et al. Structure of the bacterial flagellar protofilament and implications for a switch for supercoiling. Nature 410, 331-337 (2001).

19. De Maayer, P. \& Cowan, D. A. Flashy flagella: flagellin modification is relatively common and highly versatile among the Enterobacteriaceae. BMC Genomics 17, 377 (2016).

20. Logan, S. M. Flagellar glycosylation-a new component of the motility repertoire. Microbiology 152, 1249-1262 (2006)

21. Miller, W. L. et al. Flagellin glycosylation in Pseudomonas aeruginosa PAK requires the $\mathrm{O}$-antigen biosynthesis enzyme WbpO. J. Biol. Chem. 283, 3507-3518 (2008).

22. Szymanski, C. M., Logan, S. M., Linton, D. \& Wren, B. W. Campylobacter-a tale of two protein glycosylation systems. Trends Microbiol 11, 233-238 (2003).

23. Merino, S. \& Tomás, J. M. Gram-negative flagella glycosylation. Int J. Mol. Sci. 15, 2840-2857 (2014).

24. Stocker, B. A. D., McDonough, M. W. \& Ambler, R. P. A gene determining presence or absence of $\varepsilon-N$-methyl-lysine in Salmonella flagellar protein. Nature 189, 556-558 (1961).

25. Ambler, R. P. \& Rees, M. W. Epsilon- $N$-methyl-lysine in bacterial flagellar protein. Nature 184, 56-57 (1959).

26. Tronick, S. R. \& Martinez, R. J. Methylation of the flagellin of Salmonella typhimurium. J. Bacteriol. 105, 211-219 (1971).

27. Frye, J. et al. Identification of new flagellar genes of Salmonella enterica serovar Typhimurium. J. Bacteriol. 188, 2233-2243 (2006).

28. Deditius, J. A. et al. Characterization of novel factors involved in swimming and swarming motility in Salmonella enterica Serovar Typhimurium. PLoS ONE 10, e0135351 (2015).

29. Kanto, S., Okino, H., Aizawa, S. \& Yamaguchi, S. Amino acids responsible for flagellar shape are distributed in terminal regions of flagellin. J. Mol. Biol. 219, 471-480 (1991).

30. Yamaguchi, T. et al. Structural and Functional Comparison of Salmonella Flagellar Filaments Composed of FljB and FliC. Biomolecules 10, 246 (2020).

31. de Castro, E. et al. ScanProsite: detection of PROSITE signature matches and ProRule-associated functional and structural residues in proteins. Nucleic Acids Res. 34, W362-W365 (2006).

32. Kelly, G. et al. Structure of the cell-adhesion fragment of intimin from enteropathogenic Escherichia coli. Nat. Struct. Biol. 6, 313-318 (1999).

33. Hamburger, Z. A., Brown, M. S., Isberg, R. R. \& Bjorkman, P. J. Crystal structure of invasin: a bacterial integrin-binding protein. Science 286, 291-295 (1999).

34. Luo, Y. et al. Crystal structure of enteropathogenic Escherichia coli intiminreceptor complex. Nature 405, 1073-1077 (2000).

35. Barthel, M. et al. Pretreatment of mice with streptomycin provides a Salmonella enterica serovar Typhimurium colitis model that allows analysis of both pathogen and host. Infect. Immun. 71, 2839-2858 (2003).

36. Navabi, N., McGuckin, M. A. \& Lindén, S. K. Gastrointestinal cell lines form polarized epithelia with an adherent mucus layer when cultured in semi-wet interfaces with mechanical stimulation. PLoS ONE 8, e68761 (2013).

37. Hanson, M. S. \& Brinton, C. C. Identification and characterization of E. coli type-1 pilus tip adhesion protein. Nature 332, 265-268 (1988).

38. Ofek, I., Mirelman, D. \& Sharon, N. Adherence of Escherichia coli to human mucosal cells mediated by mannose receptors. Nature 265, 623-625 (1977).

39. Duguid, J. P. \& Campbell, I. Antigens of the type-1 fimbriae of salmonellae and other enterobacteria. J. Med. Microbiol. 2, 535-553 (1969).

40. Pratt, L. A. \& Kolter, R. Genetic analysis of Escherichia coli biofilm formation: roles of flagella, motility, chemotaxis and type I pili. Mol. Microbiol. 30, 285-293 (1998).
41. Dugail, I., Kayser, B. D. \& Lhomme, M. Specific roles of phosphatidylglycerols in hosts and microbes. Biochimie 141, 47-53 (2017).

42. Josenhans, C. \& Suerbaum, S. The role of motility as a virulence factor in bacteria. Int J. Med. Microbiol. 291, 605-614 (2002).

43. Danese, P. N., Pratt, L. A., Dove, S. L. \& Kolter, R. The outer membrane protein, antigen 43, mediates cell-to-cell interactions within Escherichia coli biofilms. Mol. Microbiol. 37, 424-432 (2000).

44. Friedlander, R. S., Vogel, N. \& Aizenberg, J. Role of flagella in adhesion of Escherichia coli to abiotic surfaces. Langmuir 31, 6137-6144 (2015).

45. Bruzaud, J. et al. Flagella but not type IV pili are involved in the initial adhesion of Pseudomonas aeruginosa PAO1 to hydrophobic or superhydrophobic surfaces. Colloids Surf. B: Biointerfaces 131, 59-66 (2015).

46. Friedlander, R. S. et al. Bacterial flagella explore microscale hummocks and hollows to increase adhesion. Proc. Natl Acad. Sci. USA 110, 5624-5629 (2013).

47. Gavín, R. et al. Lateral flagella of Aeromonas species are essential for epithelial cell adherence and biofilm formation. Mol. Microbiol. 43, 383-397 (2002).

48. Sanderson, K. E. \& Roth, J. R. Linkage map of Salmonella typhimurium, edition VII. Microbiol. Rev. 52, 485-532 (1988).

49. Datsenko, K. A. \& Wanner, B. L. One-step inactivation of chromosomal genes in Escherichia coli K-12 using PCR products. Proc. Natl Acad. Sci. USA 97, 6640-6645 (2000)

50. Mueller, U. et al. The macromolecular crystallography beamlines at BESSY II of the Helmholtz-Zentrum Berlin: current status and perspectives. Eur. Phys. J. Plus 130, 141 (2015).

51. Gerlach, M., Mueller, U. \& Weiss, M. S. The MX beamlines BL14. 1-3 at BESSY II. J. large-scale Res. Facilities JLSRF 2, 47 (2016).

52. Kabsch, W. XDS. Acta Crystallogr. D: Biol. Crystallogr. 66, 125-132 (2010).

53. McCoy, A. J. et al. Phaser crystallographic software. J. Appl. Crystallogr. 40, 658-674 (2007).

54. Emsley, P. \& Cowtan, K. Coot: model-building tools for molecular graphics. Acta Crystallogr. D: Biol. Crystallogr. 60, 2126-2132 (2004).

55. Brünger, A. T. et al. Crystallography \& NMR system: a new software suite for macromolecular structure determination. Acta Crystallogr. D: Biol. Crystallogr. 54, 905-921 (1998).

56. Krissinel, E. \& Henrick, K. Secondary-structure matching (SSM), a new tool for fast protein structure alignment in three dimensions. Acta Crystallogr. D Biol. Crystallogr. 60, 2256-2268 (2004).

57. Pettersen, E. F. et al. UCSF Chimera-a visualization system for exploratory research and analysis. J. Comput Chem. 25, 1605-1612 (2004).

58. Robert, X. \& Gouet, P. Deciphering key features in protein structures with the new ENDscript server. Nucleic Acids Res. 42, W320-W324 (2014).

59. Erhardt, M., Singer, H. M., Wee, D. H., Keener, J. P. \& Hughes, K. T. An infrequent molecular ruler controls flagellar hook length in Salmonella enterica. EMBO J. 30, 2948-2961 (2011).

60. Carvalho, P. C. et al. Integrated analysis of shotgun proteomic data with PatternLab for proteomics 4.0. Nat. Protoc. 11, 102-117 (2016).

61. Erhardt, M. Fluorescent microscopy techniques to study hook length control and flagella formation. Methods Mol. Biol. 1593, 37-46 (2017).

62. Vidal, K., Grosjean, I., evillard, J. P., Gespach, C. \& Kaiserlian, D. Immortalization of mouse intestinal epithelial cells by the SV40-large T gene. Phenotypic and immune characterization of the MODE-K cell line. J. Immunol. Methods 166, 63-73 (1993).

63. Kuehn, A. et al. Human alveolar epithelial cells expressing tight junctions to model the air-blood barrier. ALTEX 33, 251-260 (2016).

64. Pfaffl, M. W. A new mathematical model for relative quantification in realtime RT-PCR. Nucleic Acids Res. 29, e45 (2001).

65. Hansmeier, N. et al. Functional expression of the entire adhesiome of Salmonella enterica serotype Typhimurium. Sci. Rep. 7, 10326 (2017).

66. Kato, A. \& Nakai, S. Hydrophobicity determined by a fluorescence probe method and its correlation with surface properties of proteins. Biochim. Biophys. Acta 624, 13-20 (1980).

67. Alizadeh-Pasdar, N. \& Li-Chan, E. C. Comparison of protein surface hydrophobicity measured at various $\mathrm{pH}$ values using three different fluorescent probes. J. Agric. Food Chem. 48, 328-334 (2000).

68. Weinberger, A. et al. Gel-assisted formation of giant unilamellar vesicles. Biophys. J. 105, 154-164 (2013).

69. Perez-Riverol, Y. et al. The PRIDE database and related tools and resources in 2019: improving support for quantification data. Nucleic Acids Res. 47, D442-D450 (2019).

70. Maki-Yonekura, S., Yonekura, K. \& Namba, K. Conformational change of flagellin for polymorphic supercoiling of the flagellar filament. Nat. Struct. Mol. Biol. 17, 417-422 (2010).

71. Eisenberg, D., Schwarz, E., Komaromy, M. \& Wall, R. Analysis of membrane and surface protein sequences with the hydrophobic moment plot. J. Mol. Biol. 179, 125-142 (1984). 


\section{Acknowledgements}

The authors thank Heidi Landmesser, Nadine Körner, Henri Galez and Pauline Adjadj for expert technical assistance, Juana de Diego and members of the Erhardt and Kolbe labs for useful discussions and for critical comments on the manuscript and Keiichi Namba for providing the atomic model of the FliC flagellar filament. We thank HZB for the allocation of synchrotron radiation beamtime and Uwe Müller for the support at the beamline BL14.1, Petra Dersch for kindly providing plasmid pFU228, Michael Hensel for providing $\mathrm{P}_{\text {tet }}-$ fimA-F mutant strains and Tobias May (InSCREENeX GmbH) for help in tissue culture and providing the epithelial-like cell line Cl11. J.A.H. acknowledges support by the President's Initiative and Networking Funds of the Helmholtz Association of German Research Centers (HGF) under contract number VH-GS-202. This work was supported in part by the Helmholtz Association Young Investigator grant VH-NG-932 and the People Programme (Marie Curie Actions) of the Europeans Unions' Seventh Framework Programme grant 334030 (to M.E.). The Helmholtz Institute for RNA-based Infection Research (HIRI) supported this work with a seed grant through funds from the Bavarian Ministry of Economic Affairs and Media, Energy and Technology (Grant allocation nos. 0703/68674/5/2017 and 0703/89374/3/2017) (to M.E. and T.S.). M.K., M.L. and C.W. were funded by the European Research Council under the European Community's Seventh Framework Programme under grant number 311374 and through the President's Initiative and Networking Funds of the Helmholtz Association of German Research Centers (HGF). The HGF further supported T.S. by HGF impulse fund W2/ W3-066. C.U. and J.H. acknowledge funding via Leibniz grant SAW-2014-HPI-4. The Heinrich-Pette-Institute, Leibniz Institute for Experimental Virology, is supported by the Freie und Hansestadt Hamburg and the Bundesministerium für Gesundheit (BMG). H.C. and L.L. acknowledge support by the French Ministry of Higher Education, Research and Innovation. Y.R., C.R., H.C. and L.L. acknowledge funding from the European Regional Development Fund ERDF and the Region of Picardy (CPER 2007-2020). We acknowledge support by the German Research Foundation (DFG) and the Open Access Publication Fund of Humboldt-Universität zu Berlin. The funders had no role in study design, data collection and analysis, decision to publish, or preparation of the manuscript.

\section{Author contributions}

J.A.H., M.L., Y.R., M.K., and M.E. conceived the project, designed the study, wrote and revised the paper; J.A.H., M.L, H.C., L.L., M.K., J.H. and C.K. performed the experiments; J.A.H., M.L, H.C., J.H., C.K., C.U., G.A.G, Y.R., M.K., and M.E. analyzed the data; P.S.,
S.S., C.R., R.K.L., C.W., and K.T.H. contributed to experiments and performed strain construction; C.U., H.S., G.A.G., T.E.B.S., Y.R., M.K., and M.E. contributed funding and resources.

\section{Competing interests}

The authors declare no competing interests.

\section{Additional information}

Supplementary information is available for this paper at https://doi.org/10.1038/s41467 020-15738-3.

Correspondence and requests for materials should be addressed to M.K. or M.E.

Peer review information Nature Communications thanks the anonymous reviewers for their contribution to the peer review of this work. Peer reviewer reports are available.

Reprints and permission information is available at http://www.nature.com/reprints

Publisher's note Springer Nature remains neutral with regard to jurisdictional claims in published maps and institutional affiliations.

Open Access This article is licensed under a Creative Commons Attribution 4.0 International License, which permits use, sharing, adaptation, distribution and reproduction in any medium or format, as long as you give appropriate credit to the original author(s) and the source, provide a link to the Creative Commons license, and indicate if changes were made. The images or other third party material in this article are included in the article's Creative Commons license, unless indicated otherwise in a credit line to the material. If material is not included in the article's Creative Commons license and your intended use is not permitted by statutory regulation or exceeds the permitted use, you will need to obtain permission directly from the copyright holder. To view a copy of this license, visit http://creativecommons.org/ licenses/by/4.0/.

(C) The Author(s) 2020 